\title{
Bioengineering and Imaging
} Research Opportunities Workshop V: Summary of Findings on Imaging and Characterizing

\section{Structure and Function in Native and Engineered Tissues $^{1}$}

William R. Hendee, PhD

Kevin Cleary, PhD

Richard L. Ehman, MD

Gary D. Fullerton, PhD

Warren S. Grundfest

John Haller, PhD

Christine A. Kelley, PhD

Anne E. Meyer

RobertF. Murphy

William Phillips, MD

Vladimir P. Torchilin

Published online

10.1148/radiol.2482080456

Radiology 2008; 248:342-347

${ }^{1}$ From the Department of Radiation Oncology, Medical College of Wisconsin, 8701 Watertown Plank Rd, Milwaukee, WI 53226 (W.R.H.); Imaging Science and Information Systems, Georgetown University, Washington, DC (K.C.); Department of Radiology, Mayo Clinic, Rochester, Minn (R.L.E.); Department of Radiology, University of Texas Health Science Center San Antonio, San Antonio, Tex (G.D.F.); Department of Bioengineering, University of California Los Angeles, Los Angeles, Calif (W.S.G.); National Institute of Biomedical Imaging and Bioengineering (NIBIB), National Institutes of Health (NIH), Bethesda, Md (J.H.); Division of Discovery Science and Technology, NIBIB, NIH, Department of Health and Human Services, Bethesda, Md (C.A.K.); Biomaterials Graduate Program, University of Buffalo, Buffalo, NY (A.E.M.); Lane Center for Computational Biology, Carnegie Mellon University, Pittsburgh, Pa (R.F.M.); Department of Radiology, University of Texas Medical Center San Antonio, San Antonio, Tex (W.P.); and Center for Pharmaceutical Biotechnology and Nanomedicine, Northeastern University, Boston, Mass (V.P.T.). Received March 8, 2008; revision requested March 15; revision received March 26; accepted April 2; final version accepted April 7. Address correspondence to W.R.H. (e-mail: whendee@mcw.edu).

Funding:

J.H. and C.A.M. are employees of the National Insitiute of Biomedical Imaging and Bioengineering.

Authors stated no financial relationship to disclose.

๑ RSNA, 2008
Editor's Note: Similar versions of this editorial are being published in Annals of Biomedical Engineering, Cytometry Part A: The Journal of the International Society for Analytical Cytology, and Radiology so as to reach the readership of all three journals. The full report, of which this editorial represents a summary, appears in Medical Physics.

$\mathbf{T}$ he fifth Bioengineering and Imaging Research Opportunities Workshop (BIROW V) was held January 18-19, 2008. As with previous such meetings, the purpose of BIROW $\mathrm{V}$ was to identify and characterize research and engineering opportunities in biomedical engineering and imaging. The topic of the BIROW V meeting was "Imaging and Characterizing Structure and Function in Native and Engineered Tissues.”

\section{Overview}

For the fifth BIROW meeting, the name of the workshop was changed slightly from preceding workshops, which were known as Biomedical Imaging Research Opportunities Workshops, to emphasize biomedical engineering as well as imaging. BIROW $\mathrm{V}$ was sponsored by the Academy of Radiology Research (ARR), the American Association of Physicists in Medicine (AAPM), the American Institute for Medical and Biological Engineering (AIMBE), the International Society for Analytical Cytology (ISAC), and the Society for Imaging Informatics in Medicine (SIIM). Partial financial support for the meeting was furnished by the National Institute of Biomedical Imaging and Bioengineering. The purpose of BIROW V (as for the previous four BIROW meetings, which were held in 2003, 2004, 2005 and 2006) (1-4) was to identify and characterize opportunities for scientific research and engineering development in biomedical engineering and imaging.

Given the topic of BIROW V, "Imaging and Characterizing Structure and Function in Native and Engineered Tissues," the meeting focused on four areas of scientific research that offer opportunities for major developments in biomedical engineering and imaging. These four areas were (a) heterogeneous single-cell measurements and their integration into tissue and organism models; (b) functional, molecular, and structural imaging of engineered tissue in vitro and in vivo; (c) new technologies for characterizing cells and tissues in situ; and (d) imaging for targeted cell, gene, and drug delivery.

Each area was addressed in a plenary session, where several speakers presented their analysis of the subject and the research opportunities and challenges it presents. Speaker presentations were then followed by audience discussion. Each area was then the focus of discussion at one of four concurrent breakout sessions. Each breakout session provided a forum for discussion of research opportunities from the perspective of the objectives of the Roadmap program of the National Institutes of Health (5). These objectives are as follows: (a) Does it deepen understanding of fundamental biology? (b) Does it promote collaboration of multidisciplinary teams? (c) Does it reshape clinical research and promote discovery? and (d) Does it improve people's health? 
Breakout session participants were also asked to identify challenges to the realization of the research opportunities. The four questions for this section of the breakout sessions were as follows: (a) What are the scientific challenges? (b) What are the primary obstacles to development? (c) What are the critical technologies that are lacking? and $(d)$ What are the impediments to translating the opportunities to improved health?

The plenary and breakout sessions yielded a wealth of information that has been synthesized and edited into the findings and recommendations presented in this paper.

Session l: Single-Cell Measurements and Their Integration into Tissue and Organism Models

A number of conventional technologies, including imaging methods, are available for assessing the structure and function of cells and organisms in vivo. These methods yield information averaged over a volume of tissue in which the characteristics of individual cells and small groupings of cells (cell subpopulations) are not revealed. New technologies are emerging that provide an unprecedented ability to target and analyze the functions of individual cells both in vitro and in vivo. This capability presents a different challenge: How can information collected at the single-cell and cell subpopulation levels be interpreted in terms of the structural and functional integrity of the organism as a whole? This question must be addressed if the benefits of tissue engineering and regeneration are to be realized. A particular need and opportunity exists for development of methods to automatically integrate information from single-cell measurements into multiscale predictive modes.

\section{Single-Cell Measurements: Opportunities}

To understand the dynamics of a population of cells, the characteristics of individual cells and their interactions with other cells in the population must be known. This necessity demands that measurements and images be obtained at the single-cell level but with sufficient throughput to adequately sample large numbers of cells. Ongoing advances allow both flow cytometry and fluorescence microscopy to meet this need, and recent work illustrates how data on subcellular and cellular events from these technologies can be combined with machine learning methods to automatically build models (6-8). A major opportunity exists for building active learning systems that can collect a set of biologic data, build a predictive model (or improve an existing model) of the biologic process from which the data are derived, determine what new data would be needed to test the predictions of that model, and repeat the cycle of collection and model improvement. Such systems are expected to enable a greater understanding of both fundamental cell biology and how tissue-level behaviors emerge.

The evolution of single-cell measurements into tissue and organism models is interdisciplinary by its very nature and requires expertise from fields as diverse as physics, biology, chemistry, optics, electrical and biomedical engineering, imaging and computer sciences, and statistics and mathematics. As an indication of the interdisciplinary nature of the enterprise, researchers from several fields selfelected to participate in the breakout session concerned with single-cell measurements. These participants expressed the need for interdisciplinary training of people interested in working on single-cell measurements and their integration into systems models.

Single-cell and cell subpopulation measurements have the potential to greatly affect human health. Measurements in the lymphoid subpopulations of cells are critical to improved understanding of immune-mediated diseases and have already revolutionized the treatment of acquired immunodeficiency syndrome. Because they are simpler and less invasive, single-cell tests have the potential to improve patient compliance with screening tests and may lead to changes in clinical practice through earlier and improved intervention in disease and disability. Automated creation of models from single-cell measurements may be a key to individualized medicine by enabling personalized diagnosis and monitoring of response to specific treatment regimens.

\section{Single-Cell Measurements: Challenges}

A major challenge to single-cell measurements is the need for improved methods for single-cell segmentation and validation and for automated pattern characterization across cells and cell types. Also needed are improved methods for imaging live cells at high resolution (especially in vivo) and compiling atlases of protein and RNA localization across tissues and disease states. Breakout session participants noted a number of limitations that are impeding the development of single-cell and cell subpopulation measurement techniques and their integration into clinical medicine. Among these limitations are (a) insufficient resources and mechanisms for sharing and annotating images and for compiling them into image collections for the purpose of training systems for machine learning; (b) omission of image analysis details in scientific publications, so that reproduction of results is often difficult and sometimes impossible; and (c) limited availability of state-of-the-art instrumentation, computational power, and interdisciplinary scientists needed to bridge the knowledge gap between single-cell measurements, their extrapolation to higherorder scales, and their integration into tissue and organism models.

Also needed are improved labeling and sampling methods, better label-free imaging methods and in vivo sensors, more exacting standards for single-cell measurement technologies, enhanced techniques for tracking cells in the in vivo environment, and development of methods for active learning in hierarchic systems.

Session Il: Functional Molecular and Structural Imaging of Engineered Tissues in Vitro and in Vivo

Imaging methods have the potential to offer fast, noninvasive, and accurate assessments of cell growth, cell differenti- 
ation, and tissue development (including matrix development) in native and engineered tissues. Talks in this session covered two major topics: (a) molecular imaging in vivo, including noninvasive tracking and evaluation of implanted cells and the fate of three-dimensional engineered constructs, and (b) structural and functional imaging of threedimensional engineered tissue constructs in vitro. These topics encompassed a plethora of imaging techniques, including magnetic resonance (MR) imaging, micro-positron emission tomography (PET), optical coherence tomography, multiphoton microscopy, and several multimodality imaging methods. The talks and discussion emphasized the importance of communication and interaction between tissue engineering researchers and biomedical imagers to realize the potential benefits of imaging in tissue engineering and regenerative medicine.

\section{Imaging of Engineered Tissues: Opportunities}

Imaging is a critical element of tissue engineering and regenerative medicine. It has the potential to help monitor tissue function and host response in vivo and to depict implant failure early enough to permit corrective action. Further, imaging could make the processes of tissue replacement and regeneration more effective and less invasive than conventional implants. Increased imaging characterization of both natural and engineered tissues would lead to improved design of tissue engineering therapies (9).

It is widely recognized that twodimensional cell culture systems are artificial and that cells raised in these systems are phenotypically different from those grown in a three-dimensional environment. The latter cells offer a rich resource for studying cell function and cell-cell, cell-matrix, and cell-medium interactions (10). Threedimensional engineered tissue systems open new possibilities for studying complex physiologic and pathophysiologic processes in a controlled environment, including cell and tissue growth patterns and the reasons for success and failure of engineered tissues implanted in the body (11).

Tissue engineering is distinctly an interdisciplinary research effort that requires biologic, engineering, and medical knowledge tempered with input from experts in bioinformatics, computational biology, embryology, and sensor technologies. Also needed are individuals who are highly knowledgeable about the technology-transfer process, translational research, and the protection and commercialization of intellectual property. Shortfalls were acknowledged in the ability of technology-transfer offices of many academic institutions to capitalize on promising new technologies, in part because these offices are often under considerable pressure to realize short-term profits by means of early sell-off of promising new technologies at prices well below their ultimate market value. Also recognized was the need for closer involvement of clinicians with biomedical engineers and others engaged in tissue engineering.

Engineered tissues hold great promise to supplement and even replace donor tissues and biologic fluids that are perpetually in short supply (12). Threedimensional engineered tissues may become highly useful tools for development of drugs and major incentives for better imaging methods, especially when compared with animal models currently used for evaluation of drugs and imaging techniques.

\section{Imaging of Engineered Tissues: Challenges}

Imaging of engineered tissues faces many challenges, several of which are due to incomplete knowledge of cell physiology and dynamics, especially with regard to the interaction and integration of engineered and host tissues. Progress in tissue engineering requires a number of technologic innovations, including (a) noninvasive real-time imaging methods to continuously monitor cell differentiation (eg, molecular imaging of gene expression), (b) techniques for label-free imaging that are as sensitive as imaging with labels at molecular and cellular levels, (c) ways to identify and track individual cells and cell sub- populations in vivo, (d) procedures to enhance the likelihood that stem cells will seek the "proper" location when they are injected in vivo (13) and imaging techniques to verify that the desired location has been reached, and (e) processes to image cells at deeper levels within tissues and organs (14).

Other imaging advances that would accelerate the translation of tissue engineering from the laboratory to clinical use include (a) better exogenous markers and identification of additional endogenous biomarkers; (b) improved three-dimensional image analysis and quantification; (c) methods to evaluate the evolution of scaffold degradation and tissue replacement over time; (d) improved imaging procedures for automated edge detection, for deeper penetration into tissues without excessive loss of spatial resolution, and for use inside or outside a bioreactor; (e) multimodality imaging facilities and customized imaging methods, including imaging laboratories for larger animals; and ( $f$ ) better ways to compile, store, and mine imaging data. Additional concerns include the cost and nonportability of many imaging methods, the regulatory environment that inhibits the translation of new technologies into the clinic, and the need for physician awareness and acceptance of the potential of engineered tissues to address a variety of human disorders.

\section{Session IIl: New Technologies for Characterizing Cells and Tissues in Situ}

Emerging technologies are offering new approaches to the quantitative assessment of tissue properties that heretofore could not be measured in situ. Many of these technologies use imaging methods that exploit interactions of energy with tissues, and some employ the conversion of energy from one form to another (energy transduction). Examples include MR elastography $(15,16)$, photoacoustic tomography (17), thermoacoustic tomography, and ultrasoundmodulated optical tomography (18) and ultrasonographic (US) elastographic(19) and acoustic radiation forcebased methods (20). Other ap- 
proaches bring sensors and microscopic imaging techniques into contact with tissues of interest by using minimally invasive image-guided methods. Many of the emerging technologies are as adaptable to imaging tissue constructs as they are to imaging cells and cell subpopulations in vivo.

\section{Characterizing Cells and Tissues: Opportunities}

Emerging technologies improve biologic understanding by offering new methods to characterize the properties of tissues at the multicell level. They also help reveal the interplay between a target tissue and its surroundings, leading to greater knowledge of differences between normal and diseased tissue. At the microscopic scale now achievable for tissue characterization, variations in normal tissues can be measured to yield a range of normal tissue characteristics rather than just an average. Participants in the breakout session emphasized that in situ characterization of tissues could radically improve the process of clinical trials of new therapies by early monitoring of changes at cellular and tissue levels as they occur. They also recognized that emerging imaging technologies could lead to new low-cost screening methods that would be accessible to all, including populations that are currently underserved or deprived of adequate health care. Examples of such technologies include elastography for liver fibrosis (16) and endomicroscopy for in vivo cancer diagnosis (21). Realization of the potential of emerging technologies requires a multidisciplinary effort that includes physicians from the clinical arena, as well as scientists and engineers from the laboratory.

\section{Characterizing Cells and Tissues: Challenges}

Tissue characterization with emerging technologies encounters many challenges, including (a) distinguishing transient from chronic phenomena; (b) applying the technologies across multiple scales, from cells to the whole organism; (c) characterizing the interactions between focal lesions and surrounding tissues; (d) recognizing early signs of evolving health problems, such as precancerous states in cells and tissues, gene modulation by the cellular environment, and initial stages of mental illness; and (e) determining the importance of cell and tissue variables that are currently inaccessible (eg, hydrostatic pressure). In addressing these challenges, it is essential to put preconceptions aside and to think in novel ways to arrive at solutions-a rule that applies to problem solving in general and not just to tissue characterization.

The development of breakthrough technologies requires an investment of time and money beyond that awarded through the traditional funding mechanisms of federal agencies. This issue has been a perpetual problem in research funding that is slowly being addressed by federal agencies. Technologic innovation is an extremely valuable characteristic in research that should be nurtured and supported by both funding agencies and academic institutions.

To realize the benefits of new approaches to characterizing cells and tissues, better tools are needed, such as physical and chemical sensors that offer higher sensitivity, improved spatial and temporal resolution, and greater penetration of tissues. Multimodality and multiparametric probes would be helpful in measuring complementary cell and tissue characteristics, many of which are currently unmeasurable. Physicians should be brought into this effort so that the potential of these approaches can be exploited in the clinic. Finally, the cost-effectiveness of early detection and treatment of disease through methods such as cell and tissue characterization by means of imaging technologies should be emphasized as an avenue to reduction of health care costs.

\section{Session IV: Imaging for Targeted Cell,} Gene, and Drug Delivery

A major challenge in the delivery of cells, genes, and drugs to tissues is the present uncertainty about where the substances localize within cells and tissues after administration. These substances may prove to be ineffective because they do not reach the intended target in adequate amounts or because they are not retained in the target long enough to deliver the hoped-for effect. The development of new therapeutic approaches that use cells, genes, and drugs and the improvement of existing moieties depend heavily on better methods to identify and track the migration, deposition, function, and elimination of these substances in cells and tissues in the body. New imaging technologies that offer these capabilities would be a major contribution to development and application of new diagnostic and therapeutic modalities.

\section{Imaging for Target Delivery: Opportunities}

Imaging methods to track the delivery of cells, genes, and drugs in situ may contribute to a heightened understanding of basic cellular processes such as transporter and receptor kinetics, cell membrane structure, biochemical and signal pathways, endocytosis, apoptosis, and others. These methods may also reveal new information about disease biology, specific biomarkers for disease processes, and the reasons why a treatment may succeed or fail on the basis of the delivery of the therapeutic agent to the target.

Imaging studies are important to the development of new therapeutic entities and have the potential to greatly reduce the time and cost of bringing new therapies to the market and to patients. Ultimately, imaging may help match the characteristics of individual patients with the properties of specific therapeutic regimens, leading to realization of the vision of "personalized medicine" through better patient characterization and improved therapeutic products (22). To realize this potential, a multidisciplinary effort is required that includes broadly educated physicians working with scientists and engineers in the research and development of new therapies, delivery systems for the therapies, and methods to monitor the responses of patients after the therapies are administered.

\section{Imaging for Targeted Delivery: Challenges}

Major shortcomings of current therapeutic regimens that involve drugs and 
other internally administered therapies are lack of knowledge on (a) exactly where the therapies localize after administration, (b) how much of the therapies are concentrated and retained in the target tissues, (c) the uniformity of distribution of the therapies within the targeted tissues at the local level (23), and (d) what happens to the remainder of the product from the standpoint of toxicity in normal tissues. Inadequate delivery of a particular therapeutic agent to its targeted site may be the cause of ineffective therapy. To solve this problem, new drug delivery systems are needed to improve uptake and distribution of a therapeutic agent within the targeted disease process (24). Imaging of the distribution of the drug can be a key tool for development of new drug delivery systems $(25,26)$. A major challenge in the development of gene therapies is the need to track the presence, migration, and replication of viruses in the body. This challenge must be met if virus-mediated gene therapy is ever to succeed.

Several specific challenges impede the development of materials for targeted delivery in cells and tissues. These challenges include (a) inadequate standards for image guidance of therapeutic intervention in animal studies, causing difficulties in replication of results and their ultimate application in the clinic; (b) the absence of quantitative imaging methods for stem cell tracking, which are required for successful development of stem cell therapies; (c) the high cost of some commercially available imaging agents and other markers that are useful in animal and clinical studies; and (d) regulatory hurdles in gaining approval for labeling a specific therapy to permit imaging during initial clinical evaluation.

There are technologies that are essential to the evolution of more effective drugs and other therapies. Among these technologies are (a) combined imaging systems (eg, PET/computed tomography $[\mathrm{CT}]$, single photon emission computed tomography/PET, PET/MR, US/ CT) for evaluation of drug delivery, localization, and monitoring and for image-guided therapy; (b) small- and large-animal imaging facilities that are accessible to researchers exploring new cell, gene, and drug therapies; (c) optical and other new imaging modalities that can be used to guide the delivery of new therapies in animals and that can be translated into imaging techniques for the clinic; and (d) automation technologies for quantitative labeling and for image analysis.

The development of new therapies delivered by cells, genes, and drugs is expensive, and additional research funding is needed to realize their potential to alleviate human disease and suffering. In addition to core imaging facilities for small and large animals, more funding is needed to support phase 1 studies of new therapies and for translational research in general. Finally, a major effort should be directed to the interdisciplinary education and training of scientists and clinicians so that they have the integrated knowledge necessary to work productively in this new arena of medicine.

\section{Appendix}

Presenters at BIROW $\mathrm{V}$ are listed as follows:

Plenary session I: Heterogeneous Single Cell Measurements and Their Integration into Tissue and Organism Models: Polychromatic and Hyperspectral Flow Cytometry for Modeling Relationships in Heterogeneous Cell Populations, Paul Robinson, Purdue University (West Lafayette, Ind); Automated Learning of Protein Subcellular Locations for Modeling of Cell Behavior, Robert Murphy, Carnegie-Mellon University (Pittsburg, Penn); Optical Measurements and Light Distribution for the Detection of Cancer, Eva Sevick Muraca, Baylor College of Medicine (Houston, Tex); Cellular and Tissue Optical Measurements for the Detection of Colo-Rectal Cancer-Does the Field Effect Exist?: Vadim Backman, Northwestern University (Evanston, III)

Plenary session II: Functional, Molecular and Structural Imaging of Engineered Tissue in Vitro and in Vivo: The Need for Functional Imaging of Engineered Tissues, in Vitro and in Vivo,
Gordana Vunjak-Novakovic, Columbia University (New York, NY); Multi-modality Imaging of Engineered Tissues in Vivo, Charles Lin, Massachusetts General Hospital (Boston, Mass); Imaging for Design and Evaluation of Tissue Engineered Constructs, Scott Hollister, University of Michigan (Ann Arbor, Mich); Optical Imaging of Engineered Tissues, Mark Brezinski, Brigham and Women's Hospital, (Boston, Mass)

Plenary session III: New Technologies for Characterizing Cells and Tissues in Situ: Energy Transduction Imaging: PAT, TAT, UOT, Lihong Wang, Washington University (St Louis, Mo); New Technologies in Acoustical Tissue Characterization, Kathryn Nightingale, Duke University (Durham, NC); Magnetic Resonance Elastography, Richard Ehman, Mayo Clinic (Rochester, Minn); Minimally Invasive Contact Tissue Characterization: Sensors and Optical Imaging, Kevin Cleary, Georgetown Medical Center (Washington, DC)

Plenary session IV: Imaging for Targeted Cell, Gene and Drug Delivery: Dynamic Imaging of Targeted and Activatable Vehicles, Katherine Ferrara, University of California, Davis (Davis, Calif); Imaging of siRNA Delivery and Silencing, Anna Moore, Harvard Medical School (Boston, Mass); Liposomal Carriers for Drug Delivery Imaging: William Phillips, University of Texas Medical Center San Antonio; Imaging Component of Multifunctional Pharmaceutical Nanocarriers, Vladimir Torchilin, Northeastern University (Boston, Mass)

The organizers and the authors of the BIROW V white paper sincerely thank the 25 scientific and educational societies that participated by sending representatives, ideas, and other resources to make this project possible:

Sponsors: Academy of Radiology Research, American Institute of Medical and Biological Engineering, American Association of Physicists in Medicine, International Society for Analytical Cytology, and National Institute of Biomedical Imaging and Bioengineering

Participating societies: American Brachytherapy Society; American Institute of Ultrasound in Medicine; Acad- 
emy of Molecular Imaging; American Medical Informatics Association; American Roentgen Ray Society; Acoustical Society of America; Association of University Radiologists; Fleischner Society for Thoracic Imaging and Diagnosis; Institute of Electrical and Electronics Engineers (IEEE); International Society for Magnetic Resonance in Medicine; Medical Image Perception Society; North American Society for Cardiac Imaging; Radiological Society of North America; Society for Imaging Informatics in Medicine; Society of Chairs of Academic Radiology Departments; Society of Interventional Radiology; Society for Molecular Imaging; Society of Nuclear Medicine; SPIE-The International Society for Optical Engineering; Society of Radiopharmaceutical Sciences; and IEEE Ultrasonics, Ferroelectrics, and Frequency Control Society.

\section{References}

1. Carson PL, Giger M, Welch MJ, et al. Biomedical Imaging Research Opportunities Workshop: report and recommendations. Radiology 2003;229(2):328-339.

2. Hendee WR. Biomedical Imaging Research Opportunities Workshop II: a summary of findings and recommendations. Med Phys $2005 ; 32: 2484-2486$.

3. Hendee WR, Gazelle GS. Biomedical Imaging Research Opportunities Workshop III: a white paper. Ann Biomed Eng 2006;34:188198

4. Hendee WR, Banovac F, Carson PL, et al. Biomedical Imaging Research Opportunities Workshop IV: a white paper. Med Phys 2007;34:673-679.

5. Zerhouni E. Medicine: the NIH roadmap. Science 2003;302(5642):63-72.
6. Sachs K, Perez O, Pe'er D, Lauffenburger DA, Nolan GP. Causal protein-signaling networks derived from multiparameter singlecell data. Science 2005;308:523-529.

7. Ponti A, Matov A, Adams M, Gupton S, Waterman-Storer CM, Danuser G. Periodic patterns of actin turnover in lamellipodia and lamellae of migrating epithelial cells analyzed by quantitative fluorescent speckle microscopy. Biophys J 2005;89:3456-3469.

8. Zhao T, Murphy RF. Automated learning of generative models for subcellular location: building blocks for systems biology. Cytometry A 2007;71:978-990.

9. Kim K, Jeong CG, Hollister SJ. Non-invasive monitoring of tissue scaffold degradation using ultrasound elasticity imaging. Acta Biomater 2008 Feb 23 [Epub ahead of print].

10. Figallo E, Cannizzaro C, Gerecht S, et al. Micro-bioreactor array for controlling cellular environments. Lab Chip 2007;7:710719 .

11. Yamada KM, Cukierman E. Modeling tissue morphogenesis and cancer in 3D. Cell 2007; 130:601-610.

12. Mao JJ, Atala A, Mikos A, Vunjak-Novakovic $\mathrm{G}$, eds. Translational approaches in tissue engineering and regenerative medicine. Norwood, Mass: Artech House, 2008.

13. Sackstein R, Merzaban JS, Cain DW, et al. Ex vivo glycan engineering of CD44 programs human multipotent mesenchymal stromal cell trafficking to bone. Nat Med 2008;14:181-187.

14. Brezinski ME. Optical coherence tomography: principles and applications. Burlington, Mass: Academic Press, 2006.

15. Muthupillai R, Lomas DJ, Rossman PJ, Greenleaf JF, Manduca A, Ehman RL. Magnetic resonance elastography by direct visualization of propagating acoustic strain waves. Science 1995;269:1854-1857.

16. Yin M, Talwalkar JA, Glaser KJ, et al. As- sessment of hepatic fibrosis with magnetic resonance elastography. Clin Gastroenterol Hepatol 2007;5:1207-1213.

17. Zhang HF, Maslov K, Stoica G, Wang LV. Functional photoacoustic microscopy for high-resolution and noninvasive in vivo imaging. Nat Biotechnol 2006;24:848-851.

18. Sakadziæ S, Wang LV. Correlation transfer and diffusion of ultrasound-modulated multiply scattered light. Phys Rev Lett 2006; 96(16):163902.

19. Greenleaf JF, Fatemi M, Insana M. Selected methods for imaging elastic properties of biological tissues. Annu Rev Biomed Eng 2003; 5:57-78.

20. Fahey B, Nelson R, Bradway D, Hsu S, Dumont D, Trahey G. In vivo visualization of abdominal malignancies with acoustic radiation force elastography. Phys Med Biol 2008; 53:279-293.

21. Vercauteren T, Perchant A, Malandain G, Pennec X, Ayache N. Robust mosaicing with correction of motion distortions and tissue deformations for in vivo fibered microscopy. Med Image Anal 2006;10:673-692.

22. Massoud TF, Gambhir SS. Integrating noninvasive molecular imaging into molecular medicine: an evolving paradigm. Trends Mol Med 2007;13:183-191.

23. Bao A, Phillips WT, Goins B, et al. Potential use of drug carried-liposomes for cancer therapy via direct intratumoral injection. Int J Pharm 2006;316(1-2):162-169.

24. Allen TM, Cullis PR. Drug delivery systems: entering the mainstream. Science 2004;303: 1818-1822.

25. Goins BA, Phillips WT. The use of scintigraphic imaging as a tool in the development of liposome formulations. Prog Lipid Res 2001;40:95-123.

26. Torchilin VP. Targeted pharmaceutical nanocarriers for cancer therapy and imaging. AAPS J 2007;49:E128-E147. 


\section{Radiology 2008}

\section{This is your reprint order form or pro forma invoice}

(Please keep a copy of this document for your records.)

Reprint order forms and purchase orders or prepayments must be received 72 hours after receipt of form either by mail or by fax at 410-820-9765. It is the policy of Cadmus Reprints to issue one invoice per order.

Please print clearly.

Author Name

Title of Article

Issue of Journal

Number of Pages

Color in Article?

Reprint \#

$\mathrm{KB} \#$

Publication Date

Symbol Radiology

Please include the journal name and reprint number or manuscript number on your purchase order or other correspondence.

Order and Shipping Information

Reprint Costs (Please see page 2 of 2 for reprint costs/fees.)

Number of reprints ordered $\$$

Number of color reprints ordered \$

Number of covers ordered

Subtotal $\$$

Taxes

$\$$

(Add appropriate sales tax for Virginia, Maryland, Pennsylvania, and the District of Columbia or Canadian GST to the reprints if your order is to be shipped to these locations.)

First address included, add \$32 for each additional shipping address

TOTAL \$
Shipping Address (cannot ship to a P.O. Box) Please Print Clearly

Name

Institution

Street

City _ State __ Zip

Country

Quantity Fax

Phone: Day

E-mail Address Evening

Additional Shipping Address* (cannot ship to a P.O. Box)

Name

Institution

Street

City

Country

Quantity

Phone: Day

E-mail Address

* Add \$32 for each additional shipping address

\section{Payment and Credit Card Details}

Enclosed: Personal Check Credit Card Payment Details

Checks must be paid in U.S. dollars and drawn on a U.S. Bank.

Credit Card: _ VISA _ Am. Exp. _ MasterCard

Card Number

Expiration Date

Signature:

Please send your order form and prepayment made payable to:

\section{Cadmus Reprints}

P.O. Box 751903

Charlotte, NC 28275-1903

Note: Do not send express packages to this location, PO Box. FEIN \#:541274108

Signature

described in this document.

\section{Invoice or Credit Card Information}

Invoice Address Please Print Clearly

Please complete Invoice address as it appears on credit card statement

Name

Institution

Department

Street

City

Country

State

Phone

E-mail Address

Cadmus will process credit cards and Cadmus Journal Services will appear on the credit card statement.

If you don't mail your order form, you may fax it to 410-820-9765 with your credit card information.

Date 


\section{Radiology 2008}

Black and White Reprint Prices

Domestic (USA only)

\begin{tabular}{|c|c|c|c|c|c|c|}
\hline $\begin{array}{c}\text { \# of } \\
\text { Pages }\end{array}$ & $\mathbf{5 0}$ & $\mathbf{1 0 0}$ & $\mathbf{2 0 0}$ & $\mathbf{3 0 0}$ & $\mathbf{4 0 0}$ & $\mathbf{5 0 0}$ \\
\hline $\mathbf{1 - 4}$ & $\$ 221$ & $\$ 233$ & $\$ 268$ & $\$ 285$ & $\$ 303$ & $\$ 323$ \\
\hline $\mathbf{5 - 8}$ & $\$ 355$ & $\$ 382$ & $\$ 432$ & $\$ 466$ & $\$ 510$ & $\$ 544$ \\
\hline $\mathbf{9 - 1 2}$ & $\$ 466$ & $\$ 513$ & $\$ 595$ & $\$ 652$ & $\$ 714$ & $\$ 775$ \\
\hline $\mathbf{1 3 - 1 6}$ & $\$ 576$ & $\$ 640$ & $\$ 749$ & $\$ 830$ & $\$ 912$ & $\$ 995$ \\
\hline $\mathbf{1 7 - 2 0}$ & $\$ 694$ & $\$ 775$ & $\$ 906$ & $\$ 1,017$ & $\$ 1,117$ & $\$ 1,220$ \\
\hline $\mathbf{2 1 - 2 4}$ & $\$ 809$ & $\$ 906$ & $\$ 1,071$ & $\$ 1,200$ & $\$ 1,321$ & $\$ 1,471$ \\
\hline $\mathbf{2 5 - 2 8}$ & $\$ 928$ & $\$ 1,041$ & $\$ 1,242$ & $\$ 1,390$ & $\$ 1,544$ & $\$ 1,688$ \\
\hline $\mathbf{2 9 - 3 2}$ & $\$ 1,042$ & $\$ 1,178$ & $\$ 1,403$ & $\$ 1,568$ & $\$ 1,751$ & $\$ 1,924$ \\
\hline Covers & $\$ 97$ & $\$ 118$ & $\$ 215$ & $\$ 323$ & $\$ 442$ & $\$ 555$ \\
\hline
\end{tabular}

\begin{tabular}{|c|c|c|c|c|c|c|}
\hline \multicolumn{7}{|c|}{ International (includes Canada and Mexico) } \\
\hline $\begin{array}{c}\text { \# of } \\
\text { Pages }\end{array}$ & $\mathbf{5 0}$ & $\mathbf{1 0 0}$ & $\mathbf{2 0 0}$ & $\mathbf{3 0 0}$ & $\mathbf{4 0 0}$ & $\mathbf{5 0 0}$ \\
\hline $\mathbf{1 - 4}$ & $\$ 272$ & $\$ 283$ & $\$ 340$ & $\$ 397$ & $\$ 446$ & $\$ 506$ \\
\hline $\mathbf{5 - 8}$ & $\$ 428$ & $\$ 455$ & $\$ 576$ & $\$ 675$ & $\$ 784$ & $\$ 884$ \\
\hline $\mathbf{9 - 1 2}$ & $\$ 580$ & $\$ 626$ & $\$ 805$ & $\$ 964$ & $\$ 1,115$ & $\$ 1,278$ \\
\hline $\mathbf{1 3 - 1 6}$ & $\$ 724$ & $\$ 786$ & $\$ 1,023$ & $\$ 1,232$ & $\$ 1,445$ & $\$ 1,652$ \\
\hline $\mathbf{1 7}-\mathbf{2 0}$ & $\$ 878$ & $\$ 958$ & $\$ 1,246$ & $\$ 1,520$ & $\$ 1,774$ & $\$ 2,030$ \\
\hline $\mathbf{2 1 - 2 4}$ & $\$ 1,022$ & $\$ 1,119$ & $\$ 1,474$ & $\$ 1,795$ & $\$ 2,108$ & $\$ 2,426$ \\
\hline $\mathbf{2 5 - 2 8}$ & $\$ 1,176$ & $\$ 1,291$ & $\$ 1,700$ & $\$ 2,070$ & $\$ 2,450$ & $\$ 2,813$ \\
\hline $\mathbf{2 9 - 3 2}$ & $\$ 1,316$ & $\$ 1,452$ & $\$ 1,936$ & $\$ 2,355$ & $\$ 2,784$ & $\$ 3,209$ \\
\hline Covers & $\$ 156$ & $\$ 176$ & $\$ 335$ & $\$ 525$ & $\$ 716$ & $\$ 905$ \\
\hline
\end{tabular}

Minimum order is 50 copies. For orders larger than 500 copies, please consult Cadmus Reprints at 800-407-9190.

\section{Reprint Cover}

Cover prices are listed above. The cover will include the publication title, article title, and author name in black.

\section{Shipping}

Shipping costs are included in the reprint prices. Domestic orders are shipped via UPS Ground service. Foreign orders are shipped via a proof of delivery air service.

\section{Multiple Shipments}

Orders can be shipped to more than one location. Please be aware that it will cost $\$ 32$ for each additional location.

\section{Delivery}

Your order will be shipped within 2 weeks of the journal print date. Allow extra time for delivery.

\section{Color Reprint Prices}

\begin{tabular}{|c|c|c|c|c|c|c|}
\hline \multicolumn{7}{|c|}{ Domestic (USA only) } \\
\hline $\begin{array}{c}\text { \# of } \\
\text { Pages }\end{array}$ & $\mathbf{5 0}$ & $\mathbf{1 0 0}$ & $\mathbf{2 0 0}$ & $\mathbf{3 0 0}$ & $\mathbf{4 0 0}$ & $\mathbf{5 0 0}$ \\
\hline $\mathbf{1 - 4}$ & $\$ 223$ & $\$ 239$ & $\$ 352$ & $\$ 473$ & $\$ 597$ & $\$ 719$ \\
\hline $\mathbf{5 - 8}$ & $\$ 349$ & $\$ 401$ & $\$ 601$ & $\$ 849$ & $\$ 1,099$ & $\$ 1,349$ \\
\hline $\mathbf{9 - 1 2}$ & $\$ 486$ & $\$ 517$ & $\$ 852$ & $\$ 1,232$ & $\$ 1,609$ & $\$ 1,992$ \\
\hline $\mathbf{1 3 - 1 6}$ & $\$ 615$ & $\$ 651$ & $\$ 1,105$ & $\$ 1,609$ & $\$ 2,117$ & $\$ 2,624$ \\
\hline $\mathbf{1 7 - 2 0}$ & $\$ 759$ & $\$ 787$ & $\$ 1,357$ & $\$ 1,997$ & $\$ 2,626$ & $\$ 3,260$ \\
\hline $\mathbf{2 1 - 2 4}$ & $\$ 897$ & $\$ 924$ & $\$ 1,611$ & $\$ 2,376$ & $\$ 3,135$ & $\$ 3,905$ \\
\hline $\mathbf{2 5 - 2 8}$ & $\$ 1,033$ & $\$ 1,071$ & $\$ 1,873$ & $\$ 2,757$ & $\$ 3,650$ & $\$ 4,536$ \\
\hline $\mathbf{2 9 - 3 2}$ & $\$ 1,175$ & $\$ 1,208$ & $\$ 2,122$ & $\$ 3,138$ & $\$ 4,162$ & $\$ 5,180$ \\
\hline Covers & $\$ 97$ & $\$ 118$ & $\$ 215$ & $\$ 323$ & $\$ 442$ & $\$ 555$ \\
\hline
\end{tabular}

\begin{tabular}{|c|c|c|c|c|c|c|}
\hline \multicolumn{7}{|c|}{ International (includes Canada and Mexico)) } \\
\hline $\begin{array}{c}\text { \# of } \\
\text { Pages }\end{array}$ & $\mathbf{5 0}$ & $\mathbf{1 0 0}$ & $\mathbf{2 0 0}$ & $\mathbf{3 0 0}$ & $\mathbf{4 0 0}$ & $\mathbf{5 0 0}$ \\
\hline $\mathbf{1 - 4}$ & $\$ 278$ & $\$ 290$ & $\$ 424$ & $\$ 586$ & $\$ 741$ & $\$ 904$ \\
\hline $\mathbf{5 - 8}$ & $\$ 429$ & $\$ 472$ & $\$ 746$ & $\$ 1,058$ & $\$ 1,374$ & $\$ 1,690$ \\
\hline $\mathbf{9 - 1 2}$ & $\$ 604$ & $\$ 629$ & $\$ 1,061$ & $\$ 1,545$ & $\$ 2,011$ & $\$ 2,494$ \\
\hline $\mathbf{1 3 - 1 6}$ & $\$ 766$ & $\$ 797$ & $\$ 1,378$ & $\$ 2,013$ & $\$ 2,647$ & $\$ 3,280$ \\
\hline $\mathbf{1 7 - 2 0}$ & $\$ 945$ & $\$ 972$ & $\$ 1,698$ & $\$ 2,499$ & $\$ 3,282$ & $\$ 4,069$ \\
\hline $\mathbf{2 1 - 2 4}$ & $\$ 1,110$ & $\$ 1,139$ & $\$ 2,015$ & $\$ 2,970$ & $\$ 3,921$ & $\$ 4,873$ \\
\hline $\mathbf{2 5 - 2 8}$ & $\$ 1,290$ & $\$ 1,321$ & $\$ 2,333$ & $\$ 3,437$ & $\$ 4,556$ & $\$ 5,661$ \\
\hline $\mathbf{2 9 - 3 2}$ & $\$ 1,455$ & $\$ 1,482$ & $\$ 2,652$ & $\$ 3,924$ & $\$ 5,193$ & $\$ 6,462$ \\
\hline Covers & $\$ 156$ & $\$ 176$ & $\$ 335$ & $\$ 525$ & $\$ 716$ & $\$ 905$ \\
\hline
\end{tabular}

\section{Tax Due}

Residents of Virginia, Maryland, Pennsylvania, and the District of Columbia are required to add the appropriate sales tax to each reprint order. For orders shipped to Canada, please add 7\% Canadian GST unless exemption is claimed.

\section{Ordering}

Reprint order forms and purchase order or prepayment is required to process your order. Please reference journal name and reprint number or manuscript number on any correspondence. You may use the reverse side of this form as a proforma invoice. Please return your order form and prepayment to:

\section{Cadmus Reprints \\ P.O. Box 751903 \\ Charlotte, NC 28275-1903}

Note: Do not send express packages to this location, PO Box. FEIN \#:541274108

Please direct all inquiries to:

Rose A. Baynard

800-407-9190 (toll free number) 410-819-3966 (direct number) 410-820-9765 (FAX number) baynardr@cadmus.com (e-mail)
Reprint Order Forms and purchase order or prepayments must be received 72 hours after receipt of form. 